\title{
¿Cuántas versiones ofrece un autó- grafo? Las intervenciones de autor en el autógrafo de El secreto a voces de Calderón ${ }^{\top}$
}

\section{How many versions does an autograph offer? The authorial interventions in the autograph of Calderón's El secreto a voces}

\section{Simon Kroll}

Universidad de Viena

AUSTRIA

simon.kroll@googlemail.com

[Hipogrifo, (issn: 2328-1308), 2.2, 2014, pp. 63-79]

Recibido: 07-02-2014 / Aceptado: 24-03-2014

DOI: http://dx.doi.org/10.13035/H.2014.02.02.05

Resumen. La producción textual de Pedro Calderón de la Barca no cesa nunca, por lo que de numerosas comedias se conservan dos versiones. Sobre todo los autógrafos dan vivo testimonio tanto del laboratorio calderoniano como de la vida teatral del siglo XVII. Calderón parece atajar unos doscientos versos en el autógrafo de El secreto a voces, aunque cabe mencionar que no es el único que interviene en el texto atajando versos. En el presente trabajo me propongo, pues, diferenciar entre los atajos autoriales y los no-autoriales en el autógrafo de El secreto a voces.

Palabras clave. Autógrafo, atajos, correcciones de autor, versión larga, versión corta.

Abstract. Pedro Calderón de la Barca never ceases to work. His constant interest to improve or adapt his texts has produced two versions of the same play in several occasions. His autographs allow us to examine his writing process as well as the theatrical practice in Golden Age Spain. In the autograph of El secreto a voces, Calderón himself seems to delete up to 200 verses, nevertheless it also presents interventions

1. El presente trabajo forma parte del proyecto de investigación «Secrets and Secrecy in Calderón's Comedies and in Spanish Golden Age Culture» financiado por el Austrian Science Fund FWF (project number P24903-G23) y el Anniversary Fund del Oesterreichische Nationalbank (project number 14725). Le agradezco su amable ayuda a Fernando Rodríguez-Gallego durante la preparación de este artículo. 
by other hands. In this article, I will therefore try to distinguish between the authentic and non-authentic interventions in the autograph of El secreto a voces.

Keywords. Autograph, Boxed off Verses, Corrections, Long Version, Short Version.

\section{INTRODUCCIÓN: DE BORRADORES Y TRASLADOS}

«Vi una mujer... Dije mal, / vi una deidad lisonjera»². El don Juan de No hay cosa como callar evoca su recuerdo de una dama con esta hipérbole. Lo que sigue a continuación es la elaboración de la metáfora del libro de la Naturaleza, que se compara con los procesos de escritura de un libro:

$$
\begin{aligned}
& \text { Todas cuantas hermosuras, } \\
& \text { o nuestra vista celebra, } \\
& \text { o nuestro gusto apetece, } \\
& \text { fueron borradores désta } \\
& \text { porque así como un ingenio } \\
& \text { cuidadoso se desvela, } \\
& \text { cuando a públicas censuras } \\
& \text { dar algún estudio piensa, } \\
& \text { que hecho fiscal de sí mismo, } \\
& \text { un pliego rasga, otro quema, } \\
& \text { y mal contento de todo, } \\
& \text { esto borra, aquello enmienda, } \\
& \text { hasta que ya satisfecho } \\
& \text { del cuidado que le cuesta, } \\
& \text { da el borrador al traslado, } \\
& \text { y da el traslado a la imprenta; } \\
& \text { la Naturaleza así, } \\
& \text { viendo las varias bellezas } \\
& \text { que hasta entonces hizo, todas } \\
& \text { las enmendó sabia y diestra, } \\
& \text { borrando désta el defeto, } \\
& \text { y la imperfección de aquella } \\
& \text { hasta que en limpio sacó } \\
& \text { una hermosura tan bella, } \\
& \text { que más que todas divina } \\
& \text { y más que todas perfeta, } \\
& \text { fue una impresión sin errata } \\
& \text { y un traslado sin enmienda }
\end{aligned}
$$

Calderón retoca constantemente sus textos. Este afán notorio de mejorar o adaptar sus escritos ha producido en numerosos casos dos versiones de un mismo texto, proceso del que dio noticia Ruano de la Haza y recientemente Fernando Rodríguez-Gallego en sus ediciones críticas de Judas Macabeo y El astrólogo fingido4 ${ }^{4}$, respectivamente.

2. Calderón de la Barca, No hay cosa como callar, p. 1000.

3. Calderón, No hay cosa como callar, pp. 1000-1001.

4. Ruano de la Haza, 2000; Calderón, Judas Macabeo; Calderón, El astrólogo fingido. Remito además a Rodríguez-Gallego, 2010, y a la edición de El agua mansa / Guárdate del agua mansa (1990). 
En el caso afortunado de que se haya conservado el autógrafo de una obra, y en el caso concreto de El secreto a voces, éste nos ofrece la posibilidad de detectar varias redacciones de su propio texto por parte del autor.

\section{LA COPIA}

El autógrafo de El secreto a voces ${ }^{5}$ presenta en varios folios rasgos típicos de copia. Es decir, que el autor, al preparar el autógrafo que nosotros conocemos, ya tenía al menos en parte borradores delante de los que -copista de sí mismo- copiaba.

Sirva de ejemplo un homoioteleuton -salto de ojo- que se produce en el folio $45 \mathrm{v}$. Se trata de un diálogo corto entre Fabio y Federico:

$\begin{array}{ll}\text { FEDERICO } & \text { ¿Era hora, Fabio, de hallarte? } \\ \text { FABIO } & \text { Tu misma pregunta es } \\ & \text { mi respuesta, pues todo hoy } \\ & \text { te ando a buscar yo también. } \\ \text { FEDERICO } & \text { La duquesa... No te vayas, } \\ & \text { que te he menester después. } \\ \text { FABIO } & \text { No haré. (Aunque después ni antes } \\ & \text { yo a ti no te he menester). } \\ & (\text { Vv. 2706-2713) }\end{array}$

Como se puede apreciar en la ilustración 1, después del verso 2710, «La duquesa... No te vayas», Calderón vuelve a escribir el verso que Fabio ya había pronunciado poco antes: «Tu misma pregunta es». No se da cuenta inmediatamente, pero en una revisión posterior detecta el fallo, borra el verso 2711 erróneo y añade entre las líneas el verso correcto: «que te he menester después»?:

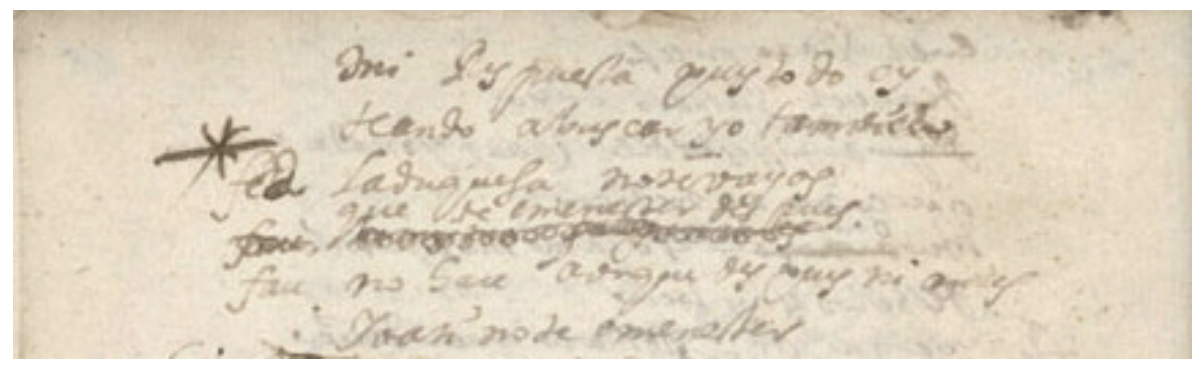

(Ilustración 1: BNE, Ms. Res/117, fol. 45v)

5. Se conserva en la BNE de Madrid: Sig. RES/117 y se puede consultar en cervantesvirtual.com.

6. Cito del texto crítico que estamos preparando.

7. Para más ejemplos de este tipo remito a nuestra edición crítica de El secreto a voces que está por publicarse. 
Otros indicios del proceso de copia serían algunos folios muy limpios. Remito como ejemplo al folio 53r, que no presenta corrección alguna.

Un editor moderno tendrá que contar por lo tanto con fallos de copista en el autógrafo de El secreto a voces. Además, esta observación revela que el autógrafo de El secreto a voces es en parte una copia en limpio que presenta ya una intentio auctoris bastante acabada.

\section{VERSOS ATAJADOS}

No obstante, Calderón volverá al autógrafo en diferentes ocasiones. Éste presenta, como muchos autógrafos calderonianos, versos tachados y versos atajados. Se tiende a pensar que éstos se deben a intervenciones por parte de los actores o autores de comedias. Los trabajos minuciosos de editores y críticos han demostrado que estas intervenciones en los originales se deben a menudo al contacto cercano que Calderón tenía con las compañías teatrales ${ }^{8}$. Estos atajos pueden causar problemas a la hora de editar el texto. Con especial cuidado habrá que tratar aquellos que provocan enmiendas en los versos adyacentes y que analizamos a continuación.

Mediante este análisis me propongo diferenciar los atajos autoriales de los no autoriales, porque me parece que una parte considerable de los atajos fueron realizados por el poeta mismo. Tomaré como punto de partida aquellas omisiones que provocaron enmiendas en los versos adyacentes.

El primer atajo de este tipo se produce en los folios $1 v$ y $2 r$ y afecta a cuatro versos de Enrique del romance inicial en é-o. Ofrezco aquí una transcripción paleográfica9:

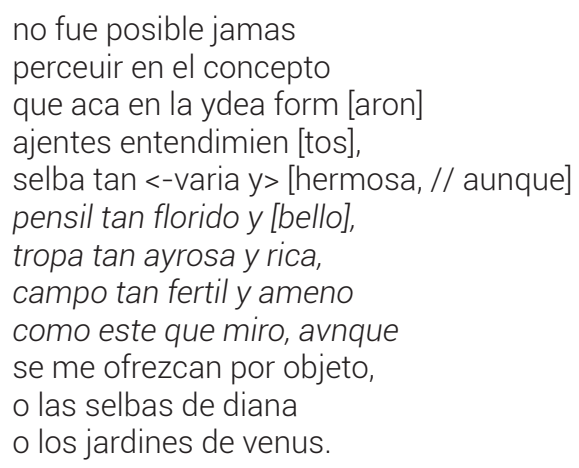

Los versos en cursiva están atajados y se distingue además dos veces no en el margen. Damos para mayor claridad la reproducción de las partes correspondientes del autógrafo:

8. Remito a Cruickshank, 2009; Rodríguez Cuadros, 2012. Las ediciones de La desdicha de la voz y de Cada uno para sí revelan a su vez la intervención de autores de comedias en los textos del dramaturgo (Calderón, La desdicha de la voz; Calderón, Cada uno para sí; Calderón, La selva confusa). 9. Sigo el modelo establecido por Presotto, 2000, p. 12. 


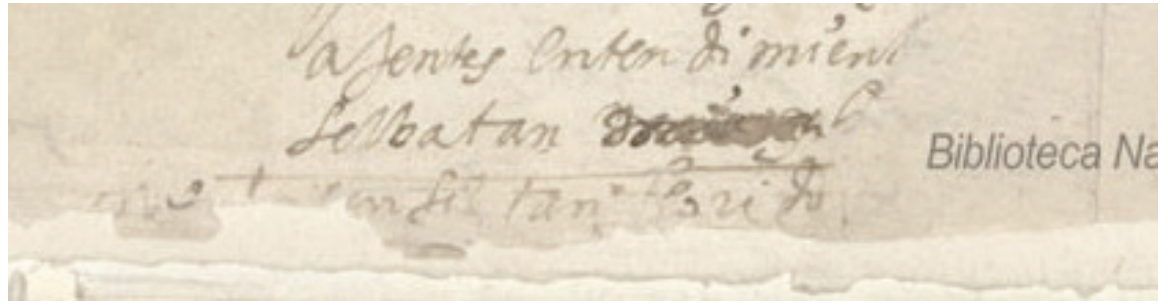

(llustración 2: BNE, Ms. RES/117, fol. 1v)

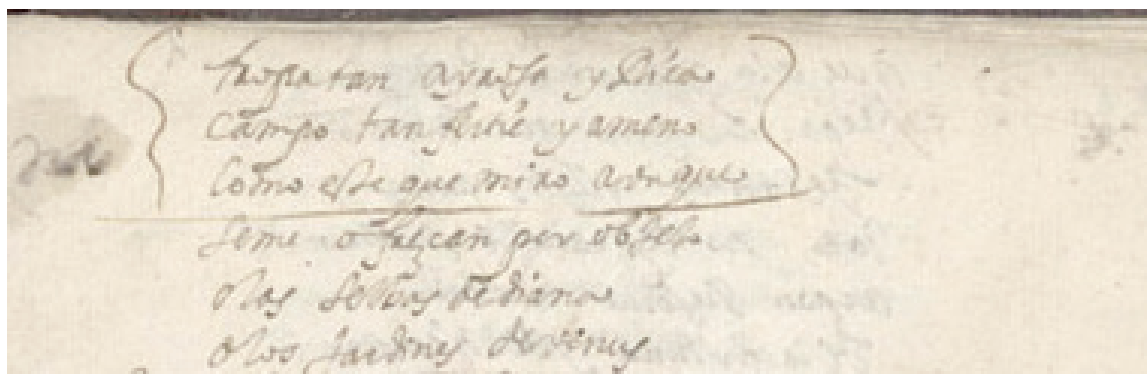

(llustración 3: BNE, Ms. RES/117, fol. 2r)

El verso anterior a la omisión se ha corregido. De «selva tan varia y hermosa» se tachó el primer adjetivo y la conjunción: varia y. Para enlazar la frase con el verso después de la omisión era necesario introducir el nexo «aunque» en este verso, lo que daría como versión final del verso: «selva tan hermosa, aunque». Es decir, que hay una versión ante correctionem ${ }^{10}$ de estos versos que rezaría:

$$
\begin{aligned}
& \text { selba tan varia y h[ermosa] } \\
& \text { pensil tan florido y [bello] } \\
& \text { tropa tan ayrosa y rica, } \\
& \text { campo tan fertil y ameno } \\
& \text { como este que miro, avnque } \\
& \text { se me ofrezcan por objeto, } \\
& \text { o las selbas de Diana } \\
& \text { o los jardines de Venus. }
\end{aligned}
$$

La versión post correctionem tendría que editarse de esta forma:

$$
\begin{aligned}
& \text { selva tan hermosa, aunque } \\
& \text { se me ofrezcan por objeto, } \\
& \text { o las selvas de Diana, } \\
& \text { o los jardines de Venus. }
\end{aligned}
$$

10. Me sirvo aquí de los términos que utiliza Coenen en su edición de La selva confusa. 
La omisión no afecta a la métrica, ni cambia el sentido dramático de los versos de Enrique. Se trata en este caso de una omisión posiblemente realizada para acortar el texto. Apunta Cruickshank: «and while the autograph version of the text has over 3,500 lines, it was originally significantly longer: Don Pedro himself deleted scores of lines by all of the major characters» ${ }^{11}$. Según mis cálculos el autógrafo cuenta con 3764 versos ante correctionem. Restando los versos tachados y los incluidos en atajos que considero autoriales resulta un texto de 3533 versos de extensión.

El caso siguiente de versos atajados se produce en el diálogo entre Flérida y Laura al final de la primera jornada. Flérida le encarga a Laura cuidar el jardín (vv. 968-975):

fler

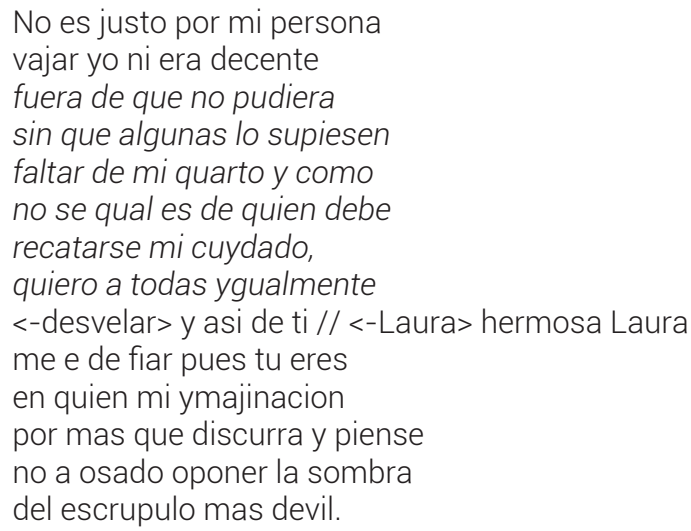

Los versos en cursiva están señalados para omitir de la misma manera que en el caso anterior. El verso adyacente («desvelar y asi de ti») se ha retocado varias veces, lo que sin lugar a dudas también se debe a la omisión de los versos anteriores.

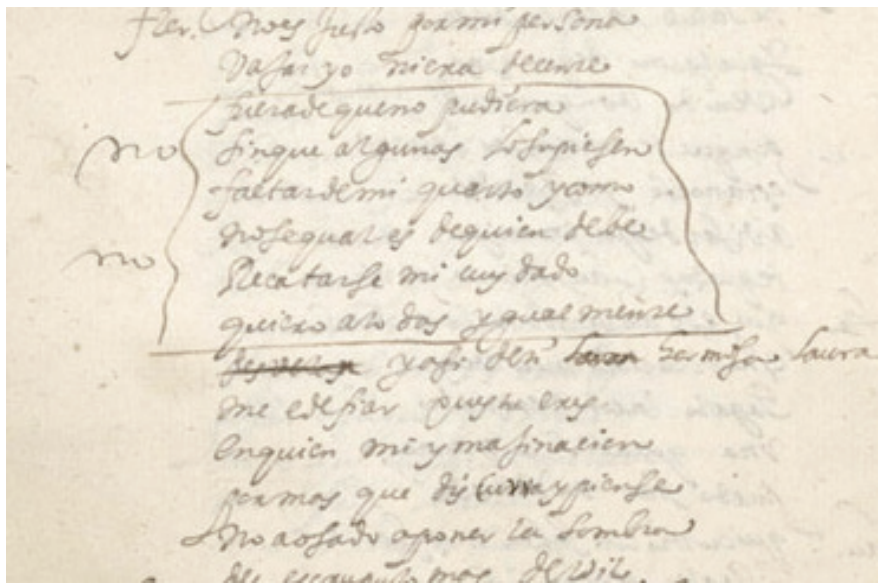

(Ilustración 4: BNE, Ms. RES/117, fol. 16v) 
La corrección en el verso después de la omisión se debe directamente a ésta, ya que la palabra tachada desvelar solo tiene sentido con el encabalgamiento del verso anterior. Al suprimirse éste, una corrección en el verso siguiente es imprescindible. Una edición que respete el atajo tendría que respetar por lo tanto también la corrección en el verso adyacente. La autoría de esta intervención aquí queda comprobada por la letra, que es indudablemente de la mano de Calderón. Una edición que quiera recuperar los versos atajados -tal es el caso de la de El secreto a voces en la Sexta Parte de Viña Liste- tendría que editar también la versión ante correctionem del verso 970 («desvelar y así de ti»). La edición de Viña Liste, sin embargo, mezcla estas dos fases del texto, ya que recupera todos los versos omitidos, pero mantiene siempre la versión post correctionem de los versos adyacentes, de tal manera que combina las lecturas ante correctionem y post correctionem del autógrafo, lo que resulta en una versión poco afortunada de estos pasajes:

FLÉRIDA No es justo, por mi persona,

bajar yo, ni era decente;

fuera de que no pudiera,

sin que algunos lo supiesen,

faltar de mi cuarto, y como

no sé cuál es de quien debe

recatarse mi cuidado,

quiero a todas igualmente.

Y así, de ti, hermosa Laura,

me he de fiar, pues tú eres

en quien mi imaginación

por más que discurra y piense,

no ha osado oponer la sombra

del escrúpulo mas débil ${ }^{12}$.

Puede observarse que el verso «quiero a todas iqualmente» carece de sentido al faltarle su complemento «desvelar», de la versión ante correctionem. Flérida, duquesa enamorada y celosa confía en un solo personaje de su corte. Que también tiene razón en desconfiar de su secretario Federico lo revela una escena de la segunda jornada en la que Flérida le acusa de trato doble con su mayor enemigo. Federico piensa que se refiere a Enrique y revela la identidad de este. Flérida en cambio se refería a la amante secreta de su secretario. De nuevo, van en cursiva los versos atajados:

fle $\quad$ yo os los dire hoy e sauido que trato doble teneis

con mi mayor enemigo

fed señora oyd que si yo

tuve en mi casa escondido

al duque de mantua fue 
sola la noche que vino

disfraçado <-no a quitaros $\backslash$ (fler) como es eso>

fed

vro estado, antes rendido

el suyo a ofreceros mas

que tirano amante fino.

fle

como es eso en vra casa

el duque cielos diuinos

no acabe cierto el enojo que a enpeçado por finjido ${ }^{13}$

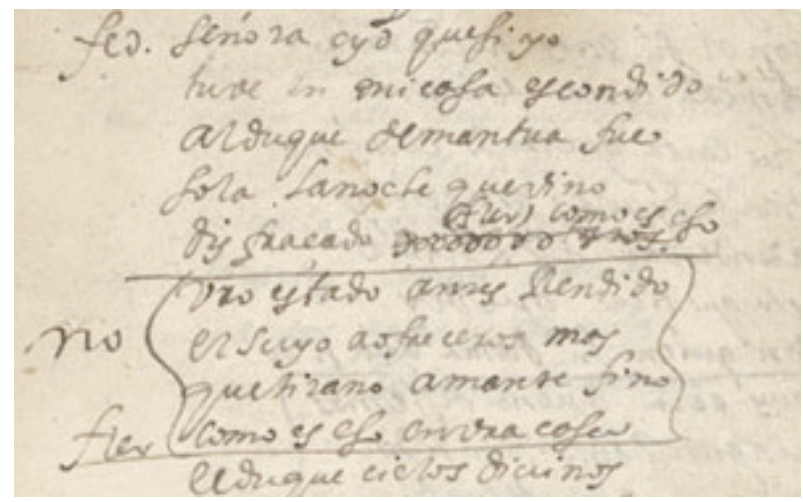

(Ilustración 5: BNE, Ms. Res/117, fol. 36r)

Como se puedo apreciar en la ilustración 5, el verso anterior al atajo se ha corregido. El segundo hemistiquio, que rezaba «no a quitaros», está tachado; se añadió otro locutor, Flérida, y la pregunta «¿Cómo es eso?». Los versos atajados no contienen ninguna información que sea necesaria para la evolución de la trama, pues la revelación de las intenciones amorosas de Enrique, aquí suprimida, se realiza algunos versos más adelante:

FEDERICO Como habiendo de casarse con vos, señora, hice juicio que de amor delitos nobles no son traidores delitos. (vv. 2256-2259)

El romance en í-o tampoco se ve afectado por la omisión y de nuevo podemos observar la mano de Calderón que interviene en el verso anterior como consecuencia del atajo. Finalmente cabe señalar que una recuperación de los versos atajados también conllevaría recuperar la versión ante correctionem del verso comentado.

Estos atajos a veces solo provocan un cambio del locutor. El clímax dramático de la segunda jornada - la casi revelación de la identidad de Laura mediante el

13. Esta parte corresponde a los versos 2235-2245 y se encuentra en el folio 36r del autógrafo. 
retrato que tiene Federico- culmina en la exclamación: «¿Cómo, / traidor, podrás resistirlo?» (vv. 2324b-2325). ¿Quién lo pronuncia? En todos los testimonios que he podido manejar, es Laura. En la versión ante correctionem del autógrafo esta pregunta es de Flérida. El locutor se ha tachado y una mano que se parece a la de Calderón escribió encima «Lau». Este cambio de locutor se debe a la omisión de veinte versos. Los versos que siguen inmediatamente a la exclamación de Laura / Flérida están atajados:

\begin{tabular}{|c|c|}
\hline$<-$ fler $>$ / lau & $\begin{array}{c}\text { ¿Como, } \\
\text { traidor, podras resistirlo? }\end{array}$ \\
\hline fed. & $\begin{array}{l}\text { Arrojandome a tus pies } \\
\text { postrado humilde y rendido } \\
\text { diciendote que esta caja } \\
\text { el onor contiene limpio } \\
\text { de vna principal señora } \\
\text { que para casarme sirbo, } \\
\text { pues con aquesto sera } \\
\text { al ser quien eres, preciso } \\
\text { que tu piedad, tu valor, } \\
\text { conbierta en premio el castigo. }\end{array}$ \\
\hline fler. & $\begin{array}{l}\text { ¿No esta el onor de esa dama } \\
\text { seguro en el pecho mio? }\end{array}$ \\
\hline fed. & $\begin{array}{l}\text { Si, señora, pero en eso } \\
\text { nada a mi me abra deuido, } \\
\text { que el ser jenerosa vos } \\
\text { no es ser yo secreto y fino. }\end{array}$ \\
\hline fler. & Yo e de verle. \\
\hline fed. & $\begin{array}{l}\qquad \begin{array}{l}\text { Pues llamad } \\
\text { quien me de muerte que vibo } \\
\text { no e de darle. }\end{array}\end{array}$ \\
\hline lau. & $\begin{array}{r}\text { ¿Como no? } \\
\text { suelta, barbaro atreuido. }\end{array}$ \\
\hline
\end{tabular}

Sale Laura por detrás y quítasele de la mano y truécale con el de Federico

fed.

Laura, ¿que haces? ${ }^{14}$

14. En nuestro texto crítico este pasaje corresponde a los versos (2324b-2326a) y en el autógrafo a los folios $37 v-38 r$. 
Como se ha podido apreciar en la recuperación de los versos omitidos, Laura solo sale al final de estos veinte versos para trocar los retratos. La acotación se encuentra en el margen derecho del folio hacia el final del atajo. La omisión de los versos provoca necesariamente el adelantamiento de la acción de Laura, que se realiza a través de la exclamación, en este caso de Laura, «¿Cómo, / traidor, podrás resistirlo?» (vv. 2324b-2325). Parece que Calderón se quería servir de todas maneras de una exclamación de Laura para encubrir la acción de trocar los retratos, ya que así sucede en ambas versiones del autógrafo - ante correctionem y post correctionem-.

El atajo no afecta el romance en í-i; además parece que el clímax se alcanza mejor si la exclamación de Laura y el intercambio de retratos se realiza al final de los versos compartidos de Laura y Federico que se ha producido en los versos anteriores (vv. 2314-2324). También nos sirve el cotejo de la letra que corrige el locutor de FLÉRIDA en LAURA, a pesar de que solo se trate de tres letras: Lau. Podemos comparar estas tres letras con muchas ocurrencias en el mismo folio que sin lugar a dudas salieron de la pluma de Calderón.

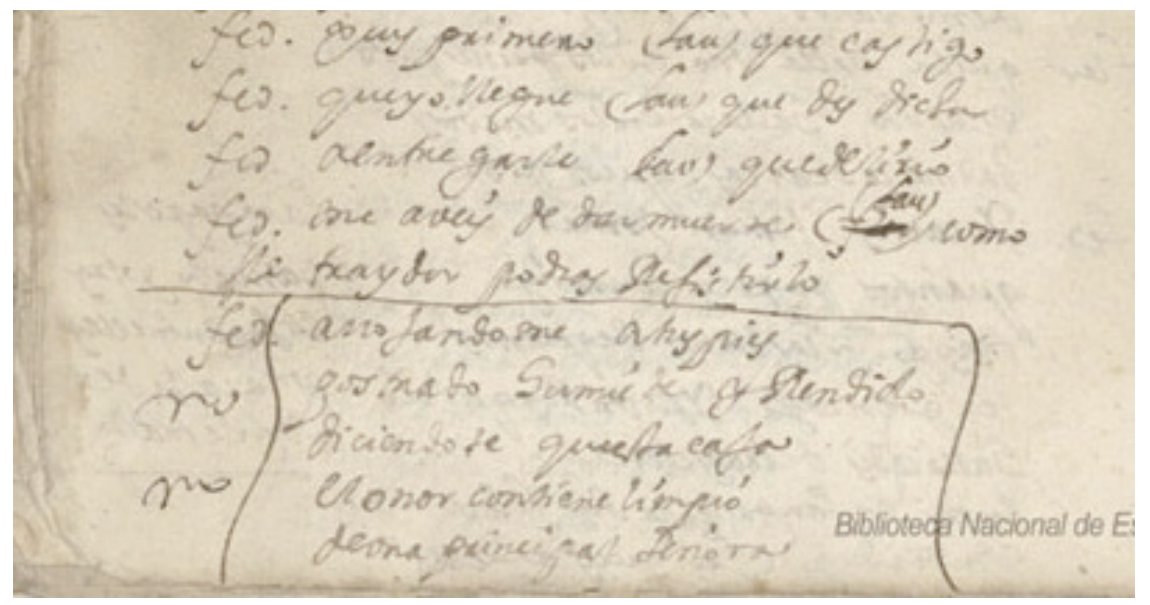

(Ilustración 6: BNE, Ms. RES/117, fol. 37v)

El parentesco es considerable. El cambio de locutor y la omisión de los veinte versos nos parecen por lo tanto intervención del autor.

Ninguno de los versos atajados analizados hasta ahora aparece en los testimonios posteriores, lo que -junto al análisis de las manos- podría ser también un indicio de haberse debido a Calderón aunque es cierto que esto puede deberse también al copista que preparó la primera copia del autógrafo. También es posible que los versos atajados que aparecen en la tradición se hayan atajado en un momento posterior a esta primera copia apógrafa del que derivan, como mostró Viña Liste, «con posibles intermediarios desconocidos, los demás testimonios que han llegado a nuestro conocimiento» ${ }^{15}$. 
La autoría del último atajo con correcciones en los versos adyacentes que queremos comentar es dudosa aunque en todo caso no se debe a Calderón. Se trata del soliloquio de Fabio al comienzo de la tercera jornada en el que este dialoga con su propia memoria.

Pero ¿qué juicio se halló perdido una vez? Volvamos, memoria, a hacer, si os parece, soliloquios otro rato.

¿Qué hay de nuevo? Dice la memoria: ¿Qué sé yo? Digo yo: ¿Qué significa que, cuando de mi amo más seguro a mi parecer me hallo, repentinamente embiste a darme dos mil porrazos? Dice la memoria: Significa que está loco. Digo yo: Y, cuando yo más culpado huyo dél, darme un vestido y hacerme dos mil halagos, memoria, ¿qué significa? Dice la memoria: Significa estar borracho.

Fuertísimas conclusiones son entrambas, y no paso a la tercera porque con Enrique viene hablando (vv. 2414-2433).

Después del verso 2417 («soliloquios otro rato») una mano añadió las palabras «mas mi amo». Una línea -la misma que rodea las palabras otro rato en el verso $2417-$ ataja los versos 2418-2432 («soliloquios otro rato... a la tercera porque»). Una mano añadió además, después del verso 2432 («a la tercera porque»), el verso «si no me miente la vista». Para mayor claridad reproducimos aquí las partes correspondientes del autógrafo:

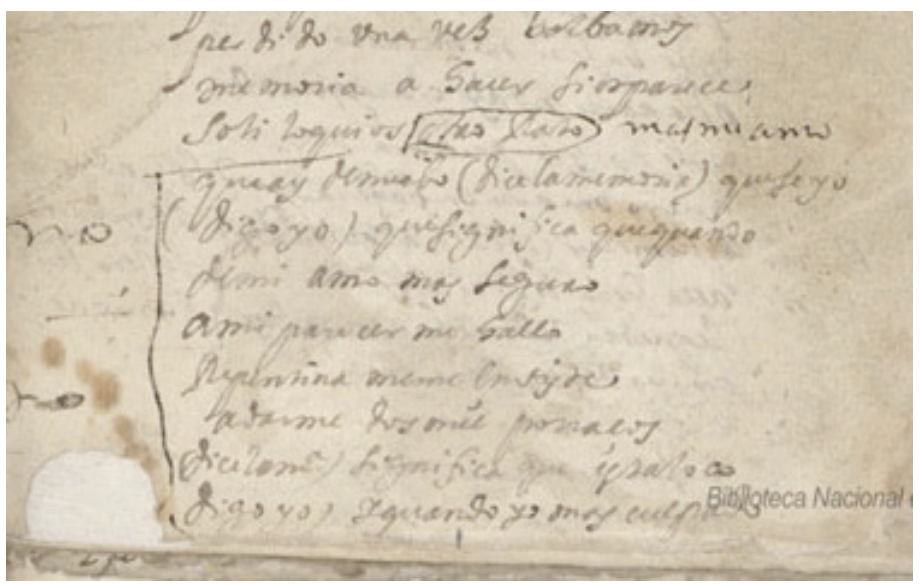

(Ilustración 7: BNE, Ms. Res/117, fol. 40r) 


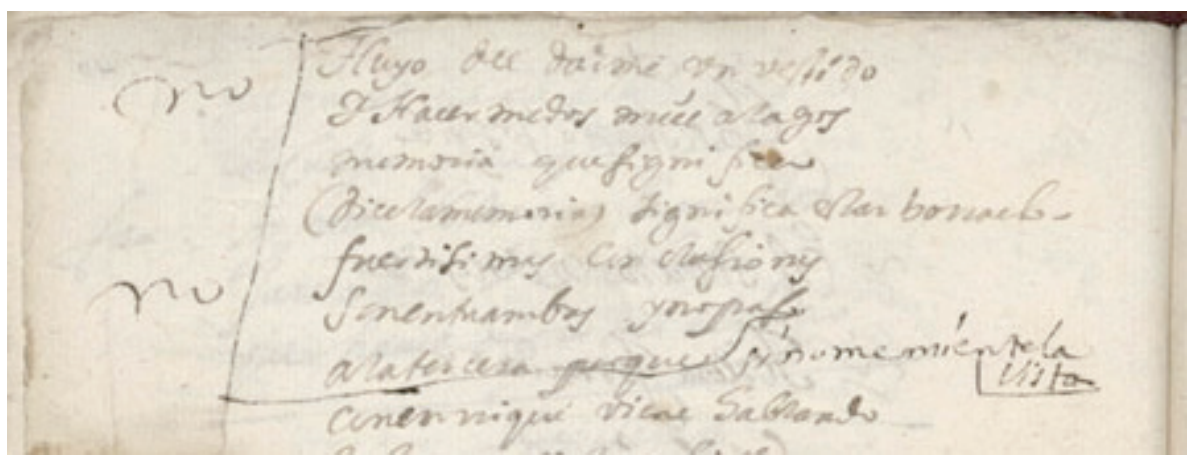

(Ilustración 8: BNE, Ms. Res/117, fol. 40v)

La mano que interviene aquí quería acortar el texto, por tanto, de la siguiente manera:

$$
\begin{aligned}
& \text { Pero, ¿qué juicio se halló } \\
& \text { perdido una vez? Volvamos, } \\
& \text { memoria, a hacer, si os parece, } \\
& \text { soliloquios. Mas mi amo, } \\
& \text { si no me miente la vista, } \\
& \text { con Enrique viene hablando. }
\end{aligned}
$$

El soliloquio quedaría omitido, aunque el romance en á-o no se ve afectado por la omisión. La mano de los versos añadidos no es la de Calderón. Además conviene mencionar que los versos de este atajo aparecen en todos los testimonios posteriores.

\section{ATAJOS SIN CORRECCIONES EN LOS VERSOS ADYACENTES}

En aquellos casos en los que el atajo provoca enmiendas en los versos adyacentes, la identificación de su autoría no presenta mayor problema. Queremos analizar a continuación algunos atajos simples, es decir, sin correcciones en los versos adyacentes, para poder establecer un catálogo de criterios para la diferenciación entre atajos autoriales y no autoriales.

Gran parte del villancico inicial se ha querido suprimir. He aquí el atajo de la segunda vuelta: 


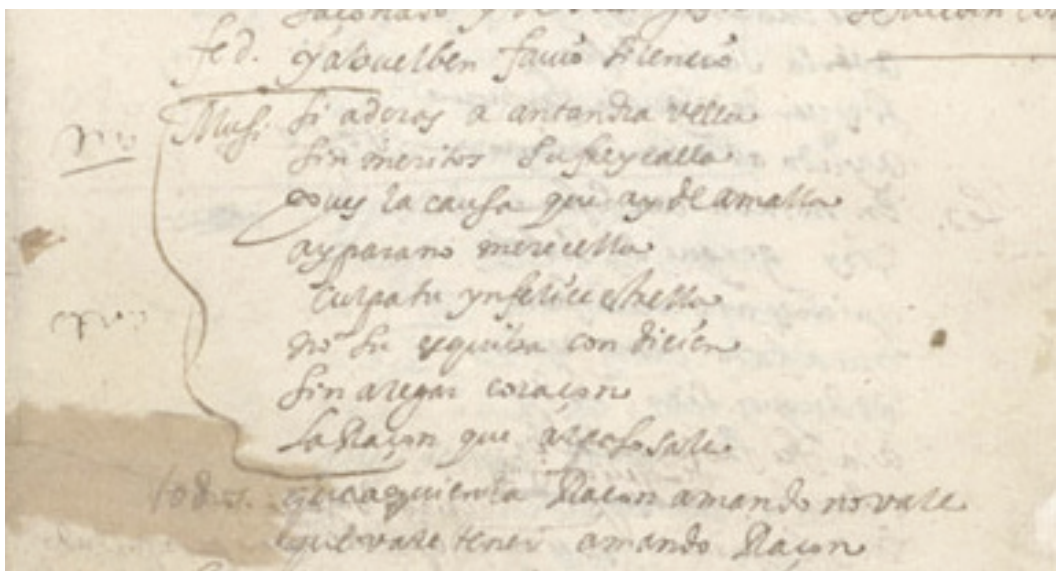

(Ilustración 9: BNE, Ms. RES/117, fol. 3v)

Omitir la mayor parte del villancico no parece una decisión muy feliz. La presencia de la música -importante en el teatro de Calderón ${ }^{16}$ - quedaría marginada. Además, Flérida hace una referencia directa a la canción al empezar su diálogo con Federico, y dice «cúya aquesa letra es» (v. 144). El diálogo que los dos emprenden gira alrededor del tema de «merecer» y «amar», que son términos clave en el villancico. Sin la estrofa de la canción, el empleo de estos tópicos estaría poco justificado. Parece al menos poco probable que Calderón haya querido suprimir la música al inicio de su obra. Los testimonios posteriores mantienen estos versos atajados.

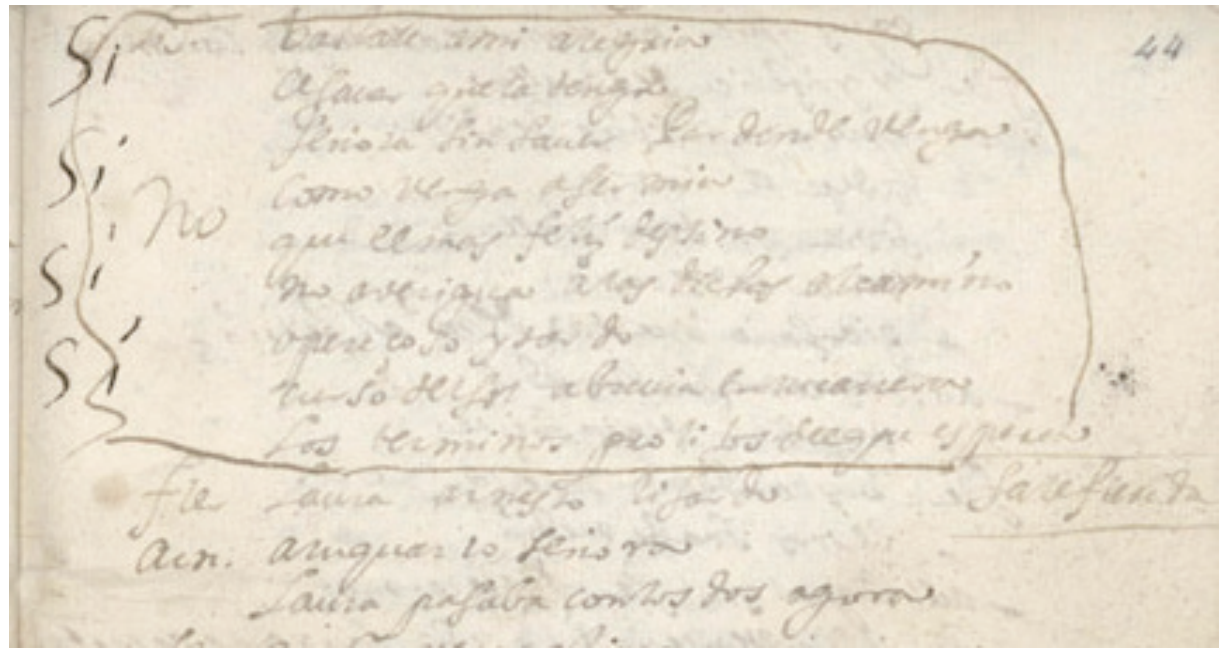

(Ilustración 10: BNE, Ms. RES/117, fol. 44r) 
Otra intervención de dudosa autoría se da en el folio 44 r (ilustración 10) y afecta a unos versos de Lisardo. Este responde a la aceptación sumisa del matrimonio por parte de Laura:

LISARDO $\quad \begin{aligned} & \text { Bástale a mi alegría } \\ & \text { el saber que la tenga, } \\ & \text { señora, sin saber por dónde venga, } \\ & \text { como venga a ser mía, } \\ & \text { que el más feliz destino } \\ & \text { no averigua a las dichas el camino. } \\ & \text { ¡Oh, perezoso y tardo } \\ & \text { curso del sol, abrevia en tu carrera } \\ & \text { los términos prolijos del que espera! (vv. 2634-2642) }\end{aligned}$

Omitir esta respuesta dejaría la situación dramática bastante tosca. Además, cabe mencionar que se rompería el esquema métrico, pues la segunda lira sestina se cortaría por el medio, por lo que también en este caso parece dudoso que Calderón sea el autor de esta intervención. Como en el caso anterior, estos versos aparecen en todos los testimonios posteriores.

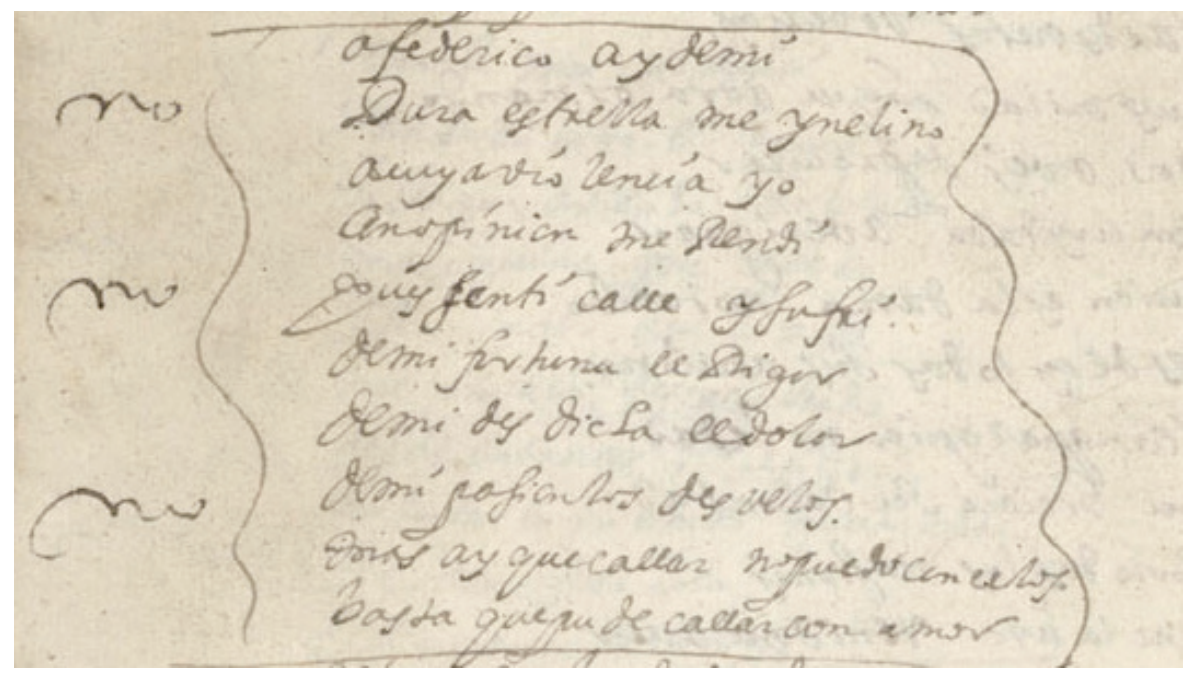

(Ilustración 11: BNE, Ms, RES/117, fol. 12v

De un soliloquio de Flérida en décimas, una se ha marcado de manera parecida a los atajos autoriales que hemos presentado al comienzo:

FLÉRIDA Loco pensamiento mío, ¿qué tirano imperio tienes en mí, que a quitarme vienes los fueros del albedrío? ¿Tanto de mí desconfío 
que ha de postrarme un temor?

¡Aquí, aquí de mi valor!

¡Aquí de mí misma, cielos!

Mas, jay!, que callar no puedo con celos;

basta que pude callar con amor.

A Federico, jay de mí!,

dura estrella me inclinó,

a cuya violencia yo

con opinión me rendí,

pues sentí, callé y sufrí

de mi fortuna el rigor,

de mi desdicha el dolor,

de mi pasión los desvelos.

Mas, jay!, que callar no puedo con celos;

basta que pude callar con amor.

¿Esta noche - iestoy dudando!-

ha de ser -iestoy muriendo!-

quedarme yo padeciendo

lo que ellos estén gozando?

Pues no ha de ser: logren cuando

yo no lo sepa el favor,

que, sabido, será error

no estorbarle. ¡Piedad, cielos!

Mas, jay!, que callar no puedo con celos;

basta que pude callar con amor! (vv. 714-733)

El esquema métrico no se rompe y ninguna información importante para la trama dramática se perdería al omitir estos versos. Incluso ganaría en sutileza, pues se omite la pronunciación del nombre de Federico por Flérida, de manera que el amor de esta por su secretario Federico no se declara abiertamente. Estos versos atajados no aparecen en los testimonios posteriores.

Para terminar quisiera establecer un catálogo de criterios para diferenciar los atajos autoriales de los no autoriales. En el caso de El secreto a voces se tendrán que tener en cuenta en primer lugar correcciones en los versos adyacentes provocadas por el atajo. Además, puede valerse de la estructura métrica, de la evolución de la trama y de la tradición posterior para diferenciar entre los atajos autoriales y no autoriales, pues se ha visto que aquellos versos atajados que, al suprimirse afectarían al esquema métrico y omitirían algún pasaje importante para la trama, aparecen todos en la tradición posterior, mientras que los versos atajados con más cuidado desaparecen en los testimonios posteriores. Para El secreto a voces creemos, por tanto, que también estos criterios menos precisos pueden utilizarse para identificar las intervenciones del poeta en su propio texto. 


\section{CONCLUSIONES}

Concluimos, pues, que en el autógrafo de El secreto a voces hay una cantidad considerable de atajos realizados por el dramaturgo mismo. Fácilmente identificables como intervenciones autoriales resultaron aquellos atajos que provocan correcciones en los versos adyacentes. Más complicados son los casos en los que ninguna corrección en los versos adyacentes puede revelar la autoría de la intervención. Para aclarar ésta se tendrá que tener en cuenta la estructura métrica, la evolución de la trama y la tradición posterior.

Con estos criterios se puede, a mi modo de ver, diferenciar con cierta probabilidad las intervenciones autoriales de las no autoriales. Si aceptamos que Calderón es el autor de algunos de los atajos, realizados por los motivos que fueren, parece, pues, que también de El secreto a voces existen por lo menos dos versiones: una larga, que incluye todos los versos ante correctionem del autógrafo, y una corta, que excluye todos los versos atajados y tachados por Calderón.

\section{BIBLIOGRAFÍA}

Calderón de la Barca, Pedro, Cada uno para sí, ed. José María Ruano de la Haza, Kassel, Reichenberger, 1982.

Calderón de la Barca, Pedro, El agua mansa / Guárdate del agua mansa, ed. Ignacio Arellano y Victor García Ruiz, Kassel, Reichenberger, 1990.

Calderón de la Barca, Pedro, El astrólogo fingido, ed. Fernando Rodríguez-Gallego, Madrid/Frankfurt, Iberoamericana/Vervuert, 2013.

Calderón de la Barca, Pedro, El secreto a voces, autógrafo, BNE, RES/117; <http:// www.cervantesvirtual.com/obra-visor/el-secreto-a-voces-manuscritocomedia-inc-razon-tienes-corazon-exp-humildes-a-vuestras-plantas--0/ $\mathrm{html} />$ [16/06/2014].

Calderón de la Barca, Pedro, El secreto a voces, ed. Wolfram Aichinger, Simon Kroll, en colaboración con Fernando Rodríguez-Gallego, Kassel, Reichenberger, 2014 (en prensa).

Calderón de la Barca, Pedro, Judas Macabeo, ed. Fernando Rodríguez-Gallego, Madrid/Frankfurt, Iberoamericana/Vervuert, 2012.

Calderón de la Barca, Pedro, La desdicha de la voz, ed. T. R. A. Mason, Liverpool, Liverpool University Press, 2003.

Calderón de la Barca, Pedro, La segunda versión de «La vida es sueño», de Calderón, ed. Germán Vega García-Luengos, Don W. Cruickshank y José María Ruano de la Haza, Liverpool, Liverpool University Press, 2000.

Calderón de la Barca, Pedro, La selva confusa, ed. Erik Coenen, Kassel, Reichenberger, 2011 
Calderón de la Barca, Pedro, No hay cosa como callar, en Pedro Calderón de la Barca, Obras completas, t. II, Comedias, ed. A. Valbuena Briones, Madrid, Aguilar, 1960, pp. 1000-1037.

Calderón de la Barca, Pedro, Comedias, VI. Sexta parte de comedias, ed. José María Viña Liste, Madrid, Biblioteca Castro, 2010.

Cruickshank, Don W., Don Pedro Calderón, Cambridge, Cambridge University Press, 2009.

Presotto, Marco, Le commedie autografe di Lope de Vega. Catalogo e studio, Kassel, Reichenberger, 2000.

Querol, Miquel, La música en el teatro de Calderón, Barcelona, Diputació de BarceIona/Institut del Teatre, 1981.

Rodríguez Cuadros, Evangelina El libro vivo que es el teatro. Canon, actor y palabra en el Siglo de Oro, Madrid, Cátedra, 2012.

Rodríguez-Gallego, Fernando, «Aproximación a la reescritura de comedias de Calderón de la Barca», en "Como en la antigua, en la edad nuestra». Presencia de la tradición en la literatura española del Siglo de Oro, ed. Natalia Fernández Rodríguez, Barcelona, Prolope, 2010, pp. 157-193.

Simson, Ingrid, «Calderón como libretista», en Calderón. Protagonista eminente del barroco europeo, ed. Kurt Reichenberger, y Theo Reichenberger, Kassel, Reichenberger, 2000, vol. I, pp. 217-243.

Viña Liste, José María, «Introducción», en Calderón de la Barca, Pedro, Comedias, VI. Sexta parte de comedias, ed. José María Viña Liste, Madrid, Biblioteca Castro, 2010, pp. XI-LXXX. 
